\title{
Los lobbies y la Tecnocracia en la Gestión Pública
}

\author{
Dr. Bernabé Aldeguer Cerdá| bernabealdeguer@gmail.com \\ Universidad de Alicante
}

\author{
Palabras clave \\ Tecnocracia, Lobby, Gestión Pública \\ Sumario \\ 1. Introducción. 2. La Tecnocracia entre lo público y lo \\ privado: nuevas tendencias de la Gerencia Pública y el \\ ejercicio de la influencia sobre la Gestión Pública. 3. \\ Consideraciones finales. 4. Bibliografía. 5. Notas
}

\begin{abstract}
Resumen
La irrupción de criterios y principios procedentes de la gestión privada o empresarial a los procesos de decisión públicos, en una circunstancia o contexto de crisis económica y financiera que trasciende las fronteras e incluso las posibilidades de las Administraciones Públicas, ha venido a recuperar la preocupación académica, así como aplicada, sobre la Tecnocracia y el papel de los lobbies en la definición, no sólo de las alternativas de elección pública, sino en la propia
\end{abstract} configuración de la agenda pública y los contornos de lo posible en la Gestión Pública. Este artículo tiene como propósito revisitar algunos aspectos que, a la luz de la contemporánea realidad institucional y política, permitan valorar el papel de los lobbies sobre la Gestión Pública. Se considera, a tales efectos y de forma especial, la relevancia de la permeable membrana de relación entre las instituciones de una parte, y los principios y las formas de gestión, no sólo públicas sino también privadas. Finalmente, el trabajo aborda algunas reflexiones sobre el uso de la información pública en el ejercicio del lobby y la influencia sobre las Administraciones Públicas o las tendencias gerenciales que han venido a incorporar a la dirección pública profesionales del ámbito privado y empresarial.

\section{Cómo citar este texto:}

Bernabé Aldeguer Cerdá (2017): "Los lobbies y la Tecnocracia en la Gestión Pública”, en Miguel Hernández Communication Journal, n8, pp. 465 a 485. Universidad Miguel Hernández, UMH (Elche-Alicante). Recuperado el __ de del artículo en mhjournal.org] de 20 _ de: link 


\title{
Lobbies and Technocracy on Public Management
}

\author{
Dr. Bernabé Aldeguer Cerdá| bernabealdeguer@gmail.com \\ Universidad de Alicante
}

\section{Keywords}

Technocracy, Lobby, Public Management.

\section{Summary}

1. Introduction. 2. The Technocracy between public and private: new tendencies of Public Management and the exercise of influence on Public Management. 3. Final considerations. 4. Bibliography. 5. Notes

\section{Abstract}

The emergence of arguments, criteria and principles from private or business management to public decision-making processes, in a circumstance or context of economic and financial crisis that transcends borders and even the possibilities of States, has come to regain academic concern on Technocracy and the role of lobbies in the definition, not only of the alternatives of public choice, but in the configuration of the public agenda itself and the contours of the possible in Public Management. This paper aims to revisit some key aspects that, considering the contemporary institutional and political reality, allow us to assess the role of lobbies in Public Management, considering the relevance of the permeable membrane of relationship between public and private institutions, principles and forms of management. We consider, particularly, the management of the public information or the managerial tendencies that have incorporated private professional and business staff to the public scope.

\section{How to cite this text:}

Bernabé Aldeguer Cerdá (2017): “Lobbies and Technocracy on Public Management", en Miguel Hernández Communication Journal, no8, pp. 465 to 485, Universidad Miguel Hernández, UMH (Elche-Alicante). Accessed _ _ _ 20_ in: [paper link in mhjournal.org] 


\section{Introducción}

El propósito del presente trabajo consiste en exponer los principales factores y tendencias que, en la época contemporánea, y de forma exploratoria, permiten describir y valorar el impacto de los lobbies y los grupos de presión sobre los procesos de adopción de decisiones, con especial referencia a la relevancia que la cualificación técnica ha adquirido en la legitimación de los discursos y las políticas públicas.

La privatización de los servicios públicos, la externalización y la creciente incorporación de agentes y actores privados en la gestión colaborativa de los mismos, junto a la proliferación de agencias y autoridades independientes de carácter regulador (especialmente en áreas de cariz técnico, como la energía o las finanzas), constituyen procesos que han venido a influenciar sobre la erosión de las fronteras entre lo público y lo privado, generando áreas de fusión y, en ocasiones también de confusión, entre ámbitos con lógicas, en principio no antagónicas, pero sí distintas, tanto en los propósitos, como en los medios y la cultura organizacional.

La irrupción de tales circunstancias y de diferentes actores procedentes del ámbito económico y civil en los procesos decisionales de carácter público, ha devenido en una variable estructural que favorecería la porosidad de las Administraciones Públicas en lo referente a las formas, los procedimientos y las estructuras de Gestión Pública, por lo que éstas vendrían a permeabilizarse respecto de la acción de los lobbies, en un escenario de creciente complejidad de las políticas públicas desde la perspectiva de la especialización técnica.

En el marco de las estrategias dirigidas a luchar contra la corrupción y favorecer la transparencia y el fortalecimiento institucional de la democracia, ha cobrado especial relevancia la regulación de la conducta y acción de los lobbies ante las instituciones y Administraciones Públicas, tanto representativas (parlamentarias) como ejecutivas (gubernamentales), con el propósito de lograr la integridad y la igualdad de oportunidades en el acceso a los recursos del poder y su influencia. Considerando este escenario, los párrafos que a continuación se desarrollan abordan las características de los grupos de presión y el ejercicio de la influencia como una dimensión relevante de la Gestión Pública, en tanto que actores orbitando en el entorno del sistema político, a la luz de lo que se ha venido a denominar como el ataque tecnocrático (Maniglio, 2015), en virtud del cual se pone constata la capacidad de los lobbies para influir, de acuerdo con sus intereses particulares, la adopción de las decisiones públicas. 
La tecnocracia ha resultado, como otros conceptos clásicos, bien en clave positiva o peyorativa, como un término sobre el que se han fundamentado algunas argumentaciones críticas, despectivas y decadentes relativas a la crisis de la democracia representativa contemporánea. Si bien, referirse a la tecnocracia requiere de una precisión previa acerca del alcance y la orientación de dicha locución: bien como referencia al perfil del conjunto humano (élites) o de los actores que la constituyen y representan, o bien como planteamiento propio de la conceptualización teórica acerca de los límites, las posibilidades o las contribuciones de la técnica y la especialización científica sobre la democracia y su rendimiento institucional, tanto en un plano teórico, como desde una lógica aplicada.

\section{La tecnocracia entre lo público y lo privado: nuevas tendencias de la gerencia pública y el ejercicio de la influencia sobre la gestión pública}

Desde una perspectiva posicional, ha resultado de interés identificar, en el organigrama formal e informal de las instituciones y sus entornos sociales y económicos, quiénes son los agentes o actores con capacidad, no sólo de influencia, sino, en su caso, de determinación política (Putnam, 1976), valorando la importancia de los criterios considerados para proceder a su reclutamiento, entre los que se contarían los parámetros técnicos y el perfil otorgado por éstos a los altos cargos, tanto políticos como directivos y burocráticos.

De forma coadyuvante, se añade a esta consideración de análisis la preocupación sempiterna por la legitimidad del sistema político en términos de eficacia y rendimiento institucional, a partir del esquema inicial formulado por Easton (1965), o la tensión entre efectividad y participación (Dahl, 1994), aproximación que ha remitido, con frecuencia, al papel de la ciencia, el manejo de la técnica y la contribución de los componentes instrumentales de la Gestión Pública en tanto que factores dirigidos a fortalecer el desempeño del entramado administrativo y, en consecuencia, el fortalecimiento institucional de la democracia.

El actual escenario de complejidad técnica en lo referente a las agendas públicas, marcadas de forma especial por la preeminencia de los asuntos económicos en la formulación de soluciones a la hodierna crisis financiera y pública, ha venido a encorsetar el debate político e ideológico en los contornos de las propuestas neoliberales, de tal suerte que "el orden político y económico que se desprende de éste ha sido aceptado casi indistintamente por 
Gobiernos de centroderecha y de centroizquierda, consagrando el principio del pensamiento único ilustrado por la máxima de Margaret Thatcher: No bay alternativa" (Anderson, 2017).

En este sentido, la relevancia de los contornos presupuestarios como claves de bóveda del discurso político, en el nivel de lo posible y lo realizable, lleva "hasta la asfixia el campo de lo factible en política económica", conforme a Vaquer (2012), a lo cual cabe añadir, en términos de Gallego, la dificultad de los poderes públicos a la hora de gestionar, eficazmente, la crisis (Gallego, 2009). No obstante, de acuerdo con Pindado Sánchez, conviene advertir sobre el hecho de que el carácter técnico de las decisiones "tenga un peso importante no significa que las prioridades no provengan de la política" (Pindado Sánchez, 2015). En cualquier caso, resulta relevante la importancia otorgada a "los costes, los resultados, la hegemonía del cliente y, más recientemente la calidad de los productos" como fundamentos a la hora de evaluar el rendimiento institucional (Olías de Lima, 2005).

En este contexto de creciente especialización técnica adquieren relevancia las comunidades epistémicas, que vendrán a verse favorecidas por la sectorialización y elevada especialización de las decisiones públicas, en un contexto en el que la cualificación instrumental irrumpe con una significativa importancia a la hora de influir sobre los procesos políticos y administrativos. La influencia de la información y su adecuada utilización en el marco de la sociedad del conocimiento hace devenir a aquella en una fuente de poder y capacidad de presión debido "a las nuevas condiciones tecnológicas que surgen en este período histórico" (Castells 1999). En este sentido, los lobbies, con entidad propia o como transmisores profesionales y profesionalizados de las exigencias o demandas propias de sus clientes sociales o económicos, no sólo cimentan su influencia en el adecuado uso de la información generada por instituciones de diversa naturaleza, como las académicas, universitarias o de investigación, sino por ser, en sí mismos, agentes creadores de conocimiento técnico por medio de la publicación de informes o la creación y coordinación de think tanks, así como por el manejo de información reservada y de trascendencia que harán impactar sobre el sistema político como un input significativo.

De esta forma, frente a organizaciones ciudadanas o movimientos sociales, e incluso ante los propios partidos políticos en tanto que actores centrales en la configuración de la institucionalidad política y administrativa, los grupos de presión y lobbies de carácter empresarial, tanto locales, pero sobre todo, y de forma creciente también transnacionales, emiten, filtran y trasladan, a través de cauces formales (altamente institucionalizados y con mecanismos regulados en 
diferente grado) o informales (de forma pública o privada), sus propuestas y recomendaciones, algunas de las cuales pasan a formar parte de los compendios normativos, en caso de que el legislador los asuma total o parcialmente.

Es, en este punto, en el que irrumpe el papel de los lobbies, no sólo a la hora de influenciar sobre políticas públicas o procesos decisionales impulsados desde las Administraciones Públicas, sino en la propia configuración de la agenda pública. En este sentido se expresó Morata al definir la influencia como la posibilidad de "incluir o excluir algún tema de la agenda pública", entre otras acciones, como la de conseguir ventajas con respecto a diferentes grupos (Morata, 1995). Como señala Martín Mangas al respecto del caso comunitario europeo, los grupos de presión pueden incidir en la propia agenda pública, haciendo llegar "a la Comisión sus reivindicaciones, por ejemplo, en orden a la modificación de la legislación" (Martín Mangas, 2004). En cualquier caso, conforme a Aller, el lobby va a contribuir a enriquecer "el conocimiento de los que tienen que legislar" (Aller, 2011).

Aunque la inquietud por el papel de la ciencia y la técnica en la política no es una circunstancia exclusiva del tiempo presente, puesto que ha estado planeando a lo largo de toda la secuencia longitudinal en la historia del pensamiento político (con el paradigmático e inicial planteamiento platónico y la más reciente formulación neoliberal), resulta obvia la especial importancia que la cualificación técnica ha adquirido en la legitimación de los discursos políticos actuales y, por tanto, en la arquitectura ideológica de las propuestas públicas planteadas al amparo del llamado Gobierno de los Expertos. Tras la formulación de la llamada gobernanza sin gobierno, en términos de Maniglio, aparece la emergencia de un conjunto de "intelectuales, técnicos, profesionales de la política (administradores)" que, tras la pátina y apariencia del interés general o, incluso del corporativismo a nivel europeo, vienen a destilar, en esencia, un conjunto de intereses particulares (Maniglio, 2015).

La derivación o desviación del locus de las decisiones públicas a discursos y ámbitos institucionales ajenos a la lógica política y democrática, pone en riesgo la posibilidad de articular los adecuados mecanismos de rendición de cuentas que permitan, en su caso, exigir las eventuales responsabilidades por las decisiones y políticas públicas adoptadas. La consolidación, como máximo exponente en Europa, del funcionamiento por el que se articulan las instituciones comunitarias europeas, en el que viene a emerger una suerte de tecnocracia corporativista fomentada por la propia naturaleza y estructura del proceso decisional (así como quizás, de la propia naturaleza económica y comercial que dio origen a la misma, por medio de la CECA, en 1957), plantea 
la disyuntiva de ahondar: 1. En el fomento de la participación plural de los agentes sociales e incluso de los propios partidos políticos o, 2. Por el contrario, dar lugar a un modelo basado en la restricción de los actores en liza, generalmente ligados a la defensa profesional(izada) de intereses, por medio de lobbies personados ante las instituciones públicas comunitarias europeas. En este sentido, Anderson destaca de qué modo, “de la Unión Monetaria (1990) al Pacto de Estabilidad (1997) y a continuación al Acta del Mercado Único (2011) y al Pacto Presupuestario (2012), los Parlamentos nacionales se vieron sustituidos por una estructura de autoridad burocrática protegida de la voluntad popular" (Anderson, 2017).

El papel concedido a los servicios técnicos de las instituciones europeas, especialmente los ligados a la Comisión, movilizan los diferentes contactos administrativos, europeos y nacionales, así como los de naturaleza privada representados, en este último caso, por los agentes reguladores o consultivos y normativos en la órbita regional y supranacional europea, también a nivel mediático, económico y profesional. Así, como señala Mangas Martín, la influencia de los expertos y funcionarios nacionales en los estadios iniciales de las decisiones incoadas por la Comisión, no se realiza en función de "un vínculo de fidelidad a su administración, sino en calidad de expertos sin representación nacional y sin instrucción o mandato" (Mangas Martín, 2004). De dicha participación se deriva, como principal ventaja para las instituciones europeas, la obtención de "datos más precisos", con un conocimiento más detallado de "la normativa y la práctica administrativa de cada Estado en la materia en cuestión", siendo en las fases germinales cuando los lobistas "tratan de hacer llegar sus ideas o incluso despiertan el interés de los servicios de la Comisión. Cuanto más esperen a influir en un proyecto, más elaborado e impermeable será a sus intereses” (Mangas Martín, 2004).

La eurocracia, en términos de Habermas, ha venido a sublimar, conceptualmente, la articulación de unas particulares relaciones entre los Estados miembros y el conjunto de las instituciones comunitarias (supranacionales) europeas, marcadas por todo un conjunto de Memorándums de Entendimiento en los que se catalogan distintas medidas de carácter bilateral por las que la UE procura garantizar el cumplimiento de una serie de estándares financieros condicionantes de las políticas nacionales, con el consiguiente acompañamiento, en su caso, de las sanciones en caso de incumplimiento. En este sentido, la dependencia financiera de los gobiernos respecto del contexto internacional facilita el fortalecimiento y protagonismo de los principios, actores y métodos de gestión de corte tecnocrático, especialmente en el marco de la presente globalización o mundialización (Scott, 1998; Dunn, 2006). 
La falta de mecanismos suficientes de control que permitan monitorizar el uso de la información o su transmisión, así como los cauces de participación por parte de los lobbies, puede poner en riesgo la exigencia y rendición de responsabilidades, al desplazar, como se ha adelantado más arriba, el centro de poder decisional (Peters, 2013). Así pues, el dilema sobre cómo configurar una estrategia de supervisión respecto del desempeño de los poderes públicos se enfrenta a la clásica preocupación sobre cómo controlar a quien tiene encomendada la competencia de controlar, "Quis custodiet ipsos custodes?", en el bien entendido de que es preciso definir los protocolos que controlarán, en sí y para sí, a los organismos públicos reguladores, consultivos o de control, que recientemente han proliferado, al objeto de monitorizar el cumplimiento de los objetivos de déficit como, por ejemplo, para el caso español, la Autoridad Independiente de Responsabilidad Fiscal (AIReF).

En este sentido, Bobbio se referiría, bajo la expresión del invisible government (Bobbio, 2013), a lo que Cervera, por su parte, llamaría los poderes paralelos; a saber: de una parte, el poder institucional o visible, y de otra, el compuesto por los superiores desconocidos (Cervera, 1984). En otras palabras, Mills analizaría, igualmente, no sólo a los llamados círculos superiores (político, negocios y militar), sino las redes que permiten cohesionar a cada uno de aquellos, más allá de lo institucional, en una comunidad de élite (Mills, 1956). Así, toda decisión política se desarrolla entre dos dimensiones, la formal y la latente (Bachrach y Baratz, 1962).

Así pues, según lo expuesto, en la medida en que el ejercicio del lobby trasciende, en mucho, más allá del ejercicio de cualquier labor de influencia directa sobre las instituciones públicas (legislativas y ejecutivas sobre todo, y en ciertos casos también judiciales) por medio de los profesionales personados ante las Administraciones Públicas, la tecnocracia encuentra oportunidades para fructificar en el ejercicio y los resultados del lobby, y muestra áreas de conjunción en las que una y otra vienen a servirse mutuamente. La tecnocracia remitirá, así, a la influencia efectiva que, desde el propio seno de las instituciones en ocasiones, adquirirá la lógica economicista y eficientista a la hora de legitimar las decisiones públicas (en las administraciones democráticas), siendo el lobby uno de los perfiles y ejercicios profesionales más paradigmáticos para la transmisión y realización de aquellos principios y sus propuestas políticas.

El papel de los grupos de presión ha venido a florecer, pues, en el contexto de unas instituciones europeas en las que se han venido a determinar, no tanto las alternativas de acción, sino los propios contornos estructurales, en términos de posibilidad financiera y presupuestaria, en el marco de los cuales se articularán 
las vías de acción o gestión. De esta forma, la tan traída y, en ocasiones, frustrante consideración sobre el déficit democrático de las instituciones europeas, viene a ahondar en el modo en que el propio diseño estructural de las Administraciones Públicas favorece el papel de los lobbies, como consecuencia del propio proceso de adopción de decisiones, marcado por la iniciativa de la Comisión y su entramado institucional de actores burocráticos -no electos-, y la posterior arquitectura de enmiendas a cargo del Parlamento y la Comisión.

De ahí que la consideración del lobby como un agente más, legítimo, en la ecología de las instituciones y su entorno, no esté exenta de la necesidad de regular un conjunto básico de principios de conducta, tal y como en el informe Lobbying in Europe ha recomendado Transparencia Internacional (TI), al señalar la importancia de articular "un lobby ético y transparente" (Mulcahy, 2015). Y es que, como ha sostenido Olías de Lima, quizás una de las tendencias más significativas en el seno de la Gestión Pública contemporánea ha venido dada por la "preocupación por la ética y los valores de empleados y directivos" (Olías de Lima, 2005), proyectándose tal inquietud o prioridad, también, sobre la actuación de los lobbies.

De acuerdo con lo anunciado más arriba, la consolidación de numerosos agentes reguladores, tanto nacionales como europeos e internacionales, cuyos cuadros directivos son reclutados desde el ámbito de la gestión empresarial privada o financiera viene, no tanto a determinar qué lobbies inciden sobre las instituciones públicas, sino los procesos que se producen en y desde el propio seno de las mismas. La membrana de intereses y actores que viene a diferenciar el ámbito público del privado deviene en porosa y permeable, no resultando identificable, en ocasiones, la naturaleza del interés ponderado a la hora de adoptar la correspondiente decisión. Sobrevuelan así, sobre la institucionalidad de los Estados, todo un conjunto de instituciones que hibridan los principios y las decisiones públicas y privadas, tales como el FMI o la llamada Troika, generando compendios de diagnóstico, pronóstico y proposición que condicionan la decisión de los poderes públicos.

Así, Malloy puso de manifiesto en qué medida los gobiernos nacionales y regionales o locales han quedado sujetos a "presiones para imponer programas impopulares de austeridad que demandan ejecutivos fuertes, apoyados en los talentos de las élites tecnocráticas" (Malloy, 1989), fortaleciendo una tecnoestructura, en términos de García Pelayo (1987), que remite, adicionalmente, a la especial y creciente atención prestada al proceso por el cual los altos directivos y cargos públicos circulan del ámbito público al privado por medio de la llamada puerta giratoria. Este proceso viene a conceptualizar, en el 
contexto de la UE, el mecanismo por medio del cual "un número preocupante de funcionarios y tecnócratas de la Comisión atraviesa la puerta giratoria, abandonando empleos en la UE para incorporarse a los grandes bancos y corporaciones y a los grupos de lobby generalmente en el mismo campo de las políticas en que trabaja" (Hernández Vigueras, 2016).

Musella ha incidido, al respecto, en la advertencia sobre la incidencia que en las políticas públicas puede llegar a tener la permeabilidad entre el desempeño privado y el público por parte de cargos públicos cuya trayectoria se desarrolla entre ambas dimensiones (la pública y la privada), en un determinado sector económico o profesional (Musella, 2015). El uso de la información a la que se ha tenido acceso en el ejercicio del cargo, tanto en lo relativo a las bases de datos documentales, como en lo referente a la agenda de contactos, que deviene en una genuina cartera de clientes, sirve como preludio a la constitución de iniciativas privadas, tales como agencias de lobby, despachos de abogados o consultorías, sublimando, de esta forma, la sospecha de que el desempeño público habría permitido la generación de oportunidades y un valor añadido al ejercicio profesional privado, como consecuencia de haber exportado un conjunto de bienes públicos dados por la información y los contactos, en aras de la influencia con fines privados.

De esta forma, en suma, las implicaciones democráticas derivadas del papel que, en cierto modo agravado, puedan asumir los lobbies a la hora de condicionar el proceso de adopción de decisiones públicas, anuncian, una vez más, los desafíos a los que las democracias representativas se enfrentan a la hora de garantizar su estabilidad, conjugando eficacia en términos de rendimiento por una parte, y la adhesión al sistema político en tanto que democrático como legitimidad difusa por otra. Ahora bien, la propia naturaleza de los topics que protagonizan la agenda pública presente, en un contexto de crisis financiera internacional, revalorizan la capacidad de influencia por parte de los agentes especializados y altamente cualificados en tal área o espacio de decisión, fructificando los actores, los principios y los procedimientos tecnocráticos como resultado, especialmente, del intercambio de criterios y cuadros entre las dimensiones pública y privada.

La irrupción en el ámbito público de profesionales o directivos reclutados o procedentes del sector privado, convierte a ciertos estamentos del ámbito profesional, financiero o empresarial, en una suerte de Caballos de Troya por mor de los cuales las instituciones públicas son colonizadas por principios economicistas que, al irrumpir en el sector público, devienen en baluartes del paladín tecnócrata. Así, y a la luz de lo anteriormente expuesto, resulta de particular relevancia la forma en que, conforme a Ormond y Löffler, "las 
reformas en la gerencia pública han cuestionado los valores tradicionales del servicio público" (Ormond y Löffler, 1999).

Más allá de las consecuencias abordadas al respecto de esta hibridación público-privada en un sentido organizacional o presupuestario, Ramió y Salvador hacen mención al factor cultural, como consecuencia de la introducción de una cultura neo-empresarial en el ámbito de la Administración Pública y el correspondiente choque cultural que, eventualmente, puede darse cuando "se introduce en unas organizaciones o ámbitos de gestión pública con una sólida cultura organizativa que agrupa valores públicos (...)" (Ramió y Salvador, 2005). En una cultura como la de las Administraciones latinas, con un menor arraigo de lo público, la introducción de valores neo-empresariales "suele comportar efectos perversos, ya que los medios (economía, eficacia y eficiencia) se transforman en fines y se pierden de vista los objetivos últimos de los programas públicos y los colectivos de ciudadanos a los que van dirigidos" (Ramió y Salvador, 2005) (Ver Tabla 1).

Tabla 1. El impacto de los valores neo empresariales sobre las culturas organizativas de los países latinos. Fuente: Ramió y Salvador. 2005.

\begin{tabular}{|c|c|c|}
\hline Cultura previa & \multirow{4}{*}{$\begin{array}{l}+\quad \text { valores neo } \\
\text { empresariales de la } \\
\text { Nueva Gestión Pública }\end{array}$} & Resultado \\
\hline $\begin{array}{l}\text { Cultura débil (escasos } \\
\text { valores } \\
\text { Mayoritario en licos). } \\
\text { administraciones latinas. }\end{array}$ & & $\begin{array}{l}\text { Cultura empresarial sin } \\
\text { valores públicos }\end{array}$ \\
\hline $\begin{array}{l}\text { Cultura fuerte (potentes } \\
\text { valores } \\
\text { Minoritario en licos). } \\
\text { administraciones latinas. }\end{array}$ & & $\begin{array}{l}\begin{array}{l}\text { Cultura de lo } \\
\text { con } \\
\text { efíblico } \\
\text { eficientistas }\end{array} \\
\text { valores }\end{array}$ \\
\hline $\begin{array}{l}\text { Cultura fragmentada } \\
\text { (valores profesionales- } \\
\text { corporativos). Presente } \\
\text { en algunos ámbitos de las } \\
\text { administraciones latinas }\end{array}$ & & Cultura variable \\
\hline
\end{tabular}

En consecuencia, frente al modelo burocrático, de cariz weberiano, se fortalece una propuesta dirigida a fomentar "una gestión flexible, orientada a los objetivos y preocupada por los resultados", introduciendo formas de gestión presididas por los principios de economía, eficiencia y eficiencia (López Camps y Gadea Carrera, 2001). Es, en este contexto, en el que el lobby pues, experimenta una cierta transformación de sus oportunidades, pudiendo 
mimetizarse con las propias instituciones, embebiéndose en las mismas a través de criterios tecnocráticos. Una de las formas de ejercer tal poder vendría dado por la aparición de instituciones que, bajo fórmulas diversas de desconcentración, y gestionadas por directivos procedentes del sector privado, ejercen funciones ejecutivas o, en su caso consultivas y normativas, con rendición posterior de responsabilidades, en su caso, por el ejercicio de sus competencias.

Uno de los elementos que ha venido adquiriendo mayor desarrollo en el marco de las reformas operadas sobre el ámbito institucional de la Gestión Pública, es el de la introducción de un nivel directivo ubicado en la interfaz política-administración, circunstancia que ha tenido una relevancia, tanto organizativa como cultural, en el sentido de que: "los directivos públicos, tanto política como profesionalmente, son decisivos en relación con la cultura organizativa. Dichos directivos, a través de sus acciones en la gestión y en el plano simbólico, fijan las normas no escritas que se transmiten al resto de la organización. De estos actores emana buena parte de los valores e ideología organizativa y sus actuaciones son las que con el tiempo configuran la mitología de la organización. Los altos funcionarios deben ser un ejemplo a la hora de transmitir los valores públicos de la organización. Los políticos que, en muchos casos, carecen de conocimientos necesarios para transmitir los valores e ideología organizativa deben ser muy cuidadosos y, al menos, tienen la obligación de no actuar en contra de los valores públicos de carácter legal o legitimados socialmente" (Ramió y Salvador, 2005)1․

La creciente importancia de los directivos o gerentes públicos se ha materializado en el ejercicio de funciones tales como la planificación y la evaluación, la dirección de la organización e implementación, la innovación y mejora de la gestión, o las relaciones con los órganos de gobierno (Longo, 1999), ubicándose el debate sobre el papel de los profesionales y directivos públicos, especialmente de los procedentes del sector privado, en el eje central de los principales procesos y ámbitos de gestión y reforma de la Administración y los servicios públicos. Ello implica la importación de una suerte de ethos de naturaleza privada o empresarial caracterizada por los principios de racionalidad económica presididos por las nociones instrumentales de eficiencia, eficacia y economía ${ }^{2}$.

En este escenario, “el interés teórico y práctico, jurídico y político sobre el régimen de los directivos públicos no ha dejado de crecer en nuestro país durante los últimos años" (Sánchez Morón, 2009). De este modo, queda justificada la regulación general que la Ley 7/2007, de 12 de abril, del Estatuto Básico del Empleado Público establece respecto del personal directivo en su 
artículo 13.1 según el cual: "El Gobierno y los Órganos de Gobierno de las Comunidades Autónomas podrán establecer, en desarrollo de este Estatuto, el régimen jurídico específico del personal directivo así como los criterios para determinar su condición, de acuerdo, entre otros, con los siguientes principios:

1. Es personal directivo el que desarrolla funciones directivas profesionales en las Administraciones Públicas, definidas como tales en las normas específicas de cada Administración.

2. Su designación atenderá a principios de mérito y capacidad y a criterios de idoneidad, y se llevará a cabo mediante procedimientos que garanticen la publicidad y concurrencia.

3. El personal directivo estará sujeto a evaluación con arreglo a los criterios de eficacia y eficiencia, responsabilidad por su gestión y control de resultados en relación con los objetivos que les hayan sido fijados.

4. La determinación de las condiciones de empleo del personal directivo no tendrá la consideración de materia objeto de negociación colectiva a los efectos de esta Ley. Cuando el personal directivo reúna la condición de personal laboral estará sometido a la relación laboral de carácter especial de alta dirección”.

En suma, el actual escenario institucional ha venido a conceder oportunidades para la inclusión de principios y cuadros profesionales de cariz tecnocrático en el ámbito de la Gestión Pública. Si bien, el protagonismo que, en los últimos años, ha adquirido la inclusión de temas altamente especializados y de complejidad técnica, como los ligados a la gestión de la crisis financiera pública, ha constituido un factor procedente del entorno en el cual han fructificado los posicionamientos economicistas, como consecuencia de la preeminencia argumental asociada a los programas de austeridad a nivel europeo.

\section{Consideraciones finales.}

Los grupos de presión, por medio de lobbies, ejercen su influencia en entornos propicios al efecto, siendo preferentemente aquellos en los que operan factores de alta especialización técnica, circunstancia en la que las fuerzas económico-sociales pueden presionar sobre los altos estamentos funcionariales y administrativos, especialmente en los momentos iniciales del trámite, en los que, tomando el ejemplo europeo, el competente en la elaboración de la propuesta "concilia un método funcionalista de análisis racional y técnico en la aproximación a los objetivos comunes, una influyente presión transnacional y 
una inquietante permeabilidad a los elementos intergubernamentales" (Martín Mangas, 2004).

La actual situación de crisis financiera, con claro impacto sobre el diseño estructural y el funcionamiento de las Administraciones Públicas y sus entramados decisionales, se ha unido a un conjunto de procesos que han fomentado el papel desempeñado por la cualificación técnica y la incorporación de principios, métodos e instrumentos procedentes del sector privado, de entre todos los cuales cabría destacar los siguientes:

- La proliferación de procesos de contratación pública ligados al recurso creciente que lo público ha realizado de lo privado para la prestación de servicios asumidos, de forma exclusiva y hasta el momento, por el personal y la organización administrativa del Estado y su Sector Público;

- La consolidación del partenariado como "un phénomène dans l'administration et la gestión publiques" (Revue Internationale des Sciences Administratives, 2004);

- El desarrollo de procesos de privatización de servicios públicos o, en su caso, la concesión y concertación para la prestación de los mismos con agentes, organizaciones y empresas del sector privado, bajo fórmulas tales como:

- Gestión interesada;

- Concierto;

- Sociedad de economía mixta; o,

- Concesión administrativa (Quintans García, 2003).

- La reducción de las prestaciones de carácter social, trasladándose dicha responsabilidad a instituciones y organizaciones del llamado Tercer Sector a la hora de ejercer y gestionar actividades prestacionales otrora incluidas en el corazón del catálogo de servicios asumidos por el Estado del Bienestar;

- La desregulación de los servicios y sectores económicos estratégicos, de entre los que cabría destacar el financiero, así como la financiarización de la economía productiva y las finanzas públicas, marcadas éstas últimas por el control de los niveles de déficit y deuda pública;

- La contratación e incorporación, en su caso, a la gestión pública, de directivos y profesionales procedentes del sector privado, tanto empresarial como financiero, como se ha señalado más arriba; y,

- La implantación de un conjunto de medidas estructurales de carácter presupuestario y financiero en el marco de la llamada austeridad, que 
habiendo sido constitucionalizadas (como para el caso español sucedió el año 2011) fruto de lo dispuesto al respecto en el Tratado de la Unión Europea (1992) en lo relativo a los límites de deuda y déficit público, han impregnado el conjunto de las políticas presupuestarias (TUE, 1992).

En el marco de la OCDE, el objeto de las reformas impulsadas ha avanzado en el cambio de modelo respecto de los siguientes puntos (Rodríguez Álvarez, 1997) ${ }^{3}$ :

- "Mayor atención a los resultados y obtener mejor relación calidad/precio.

- Transferir competencias y lograr una mayor flexibilidad.

- Una responsabilidad y un control fortalecidos.

- Una orientación hacia el cliente y el servicio.

- Una mayor capacidad de definición de las estrategias y de las políticas.

- Introducir la competencia y otros elementos del mercado.

- Modificar las relaciones con los otros niveles administrativos" (OCDE, 1997).

Como resultado, las consecuencias derivadas de las reformas y los ajustes materializados en el marco del paradigma dominante en las recientes décadas, han sido las siguientes (Ormond y Löffler, 1999):

- Corporatización o semi-privatización.

- Nuevas formas de organización en el sector público. V. gr.: cuerpos (semi-) autónomos.

- "La mayor libertad gerencial en el seno de las organizaciones públicas permite también más oportunidades para un comportamiento irregular" (Ormond y Löffler, 1999).

- Se ha difuminado la frontera entre el sector público y el sector privado.

La crisis de confianza en términos democráticos de la legitimación discursiva e ideológica de la Gestión Pública, realza el recurso a la argumentación basada en criterios de eficiencia económica y necesidad (frente a la ausencia de posibles alternativas). De esta forma, el debate político queda trufado de informes, textos y documentos de origen privado y profesional que sirven de sustento para legitimar y fundamentar las propuestas alternativas, de tal suerte que la falta de remisión a cualquier planteamiento meta-político o metaideológico, desacredita, por parcial, incompleto o voluntarista, aquello por lo que se apuesta y pretende a nivel programático. Una de las líneas de regulación en el funcionamiento y la actuación del lobby ha venido dada, en este sentido, 
por la necesidad de aportar, en el transcurso parlamentario de las medidas legislativas, la documentación que ha servido de fundamento o referencia, al legislativo o decisor público, para la adopción de las medidas por las que se ha optado en la esfera normativa, o bien en el nivel de las políticas públicas. Se impone así, en términos de Tourine, una nueva institucionalidad de la democracia (Tourine, 1993).

No existe a día de hoy oposición en sí a la existencia y participación legítima de los lobbies en lo referente a su actividad de influencia sobre las Administraciones Públicas, en el marco de un modelo representativo de democracia, con fórmulas de audiencia en la Gestión Pública que trascienden la participación e interlocución social reconocida a los diferentes actores sociales y económicos, así como al conjunto de la sociedad. Si bien, ello no es óbice para soslayar la necesidad de regular y disponer de mecanismos que alerten y regulen las cautelas que puedan permitir, en su caso, la superación de las eventuales irregularidades que pudieran producirse en el proceso de influencia. Y es que, de acuerdo con Barber, los déficits de las democracias pluralistas adolecen de los déficits procedentes de las "ficciones del libre mercado y de la libertad e igualdad de los agentes negociadores" (Barber, 1998), como resultado de la asimetría consustancial a la presencia de diferentes agentes, destacando de entre todos ellos los lobbies, con recursos claramente desequilibrados, que inciden en la capacidad de influenciar sobre el proceso decisional.

El uso de información cualificada y la disposición de instrumentos técnicos susceptibles de pugnar, en su caso, con el instrumental documental y analítico de las propias Administraciones Públicas, puede llegar a poner en riesgo la equilibrada participación que, en condiciones de igualdad, pueden llegar a ejercer, en la lógica democrática, los lobbies, en el bien entendido de que, conforme a Przeworski, ningún actor debiera tener la capacidad de controlar "el desarrollo de los hechos" (Przeworski, 1995), por lo que, frente a la exclusiva legitimación eficientista de la reforma administrativa, resulta preciso alumbrar nuevas perspectivas de fortalecimiento democrático, tanto en la esfera institucional, como en la dimensión social.

\section{Bibliografía}

Aller, M. (2011). "Lobby. La voz de la influencia”, en Actualidad Económica, Feb, pp. 42-46. 
Anderson, P. (2017). "Agitación antisistema en Europa y en Estados Unidos", en Le Monde diplomatique en español, Marzo, pp. 18-19.

Bachrach, P. y Baratz, M. S. (1962). "Two faces of power", American Political Science Review, 56, pp. 947-952.

Barber, B. (1998). "Democracia fuerte: un marco conceptual, política de participación”, en Águila, R. y Vallespín, F. La democracia en sus textos. Madrid: Alianza.

Bobbio, N. (2013). Democracia y secreto. Traducción Ariella Aureli-José F. Fernández Santillán. México: FCE.

Cervera, J. A. (1984). La red del poder. Madrid: Ediciones Dyrsa.

Dahl, R. (1994). "A democratic dilema: system efectiveness versus citizen participation”, Political Science Quarterly, Vol. 109, n 1, pp. 23-24.

Dunn, J. (2006). “How democracies succeed”, Economy and Society, no 25 (4), pp. 511-528.

Easton, D. (1965). A Systems Analysis of Political Life. Nueva York.

Gallego, M T. (2009). "Estado Social y crisis del Estado”, en Del Águila, R. Manual de Ciencia Política. Madrid: Trotta.

García Pelayo, M. (1987). Burocracia y Tecnocracia. Madrid: Alianza.

Hernández Vigueras, J. (2016). Los lobbies financieros, tentáculos del poder. Madrid: Clave Intelectual.

Longo, F. (1999). Politica y Servicio público en los gobiernos locales. Gobierno Localy modelo gerencial. Barcelona: Fundació Pi i Sunyer, pp. 21-54.

López Camps, J. \& Gadea Carrera, A. (2001). "Una nueva administración pública: estrategias y métodos para mejorar la calidad y la eficiencia del eGobierno", Oñati: Instituto V asco de Administración Pública.

Malloy, J. M. (1989). "Policy analysis, public policy and regime structure in Latin America”, Governance, Vol. 2, No 3, pp. 315-338. 
Mangas Martín, A. (2004). "Las relaciones interinstitucionales y la dinámica del proceso de decisión”, en Mangas Martín, A. y Liñán Nogueras, D. L. Instituciones y Derecho de la Unión Europea. Madrid: Tecnos.

Maniglio, F. (2015). "Dirigir sin gobernar en la Sociedad del Conocimiento. El despotismo ilustrado en el discurso del techno-corporatism europeo”, en Discurso y Sociedad, Vol. 9 (3), pp. 296-330.

Martín-Castilla, J. (2004). "La dimensión ética del liderazgo en la Administración Pública”, XII Conferencia Anual de Ética, Economía y Dirección. Ética y Finanzas. Úbeda (Jaén), 3-4 Junio 2004.

Mills, C. W. (1956). La élite del poder. Reimpresión en 2000. New York: Oxford University Press.

Morata, F. (1995). "Influir para decidir: la incidencia de los lobbies en la Unión Europea”, en Revista de Estudios Políticos, no 90, Oct-Dic, pp. 129-146.

Mulcahy, S. (2015). Lobbying in Europe. Influencia encubierta, acceso privilegiado. Transparencia Internacional.

Musella, F (2015). "Presidents in business. Career and destiny of democratic leaders”, European Political Science Review, 7 (2), pp. 293 - 313.

Olías de Lima, B. (2005). "Servicios Públicos y Gobernanza", Revista Sistema, $\mathrm{n}^{\mathrm{o}} 184$, pp. $125-140$.

Ormond, D. y Löffler, E. (1999). "Nueva Gerencia Pública, ¿Qué tomar y qué dejar?”, Reforma y Democracia, no 13.

Peters, G. (2013). “The future of Public Administration”, en Bickerton, J. \& Peters, G. (ed.). Governing. Essays in honour of Donald J. Savoie. London: Mc GillQueen's University Press.

Peters, G. (2013). "The future of Public Administration", en Bickerton, J. \& Peters, G. (ed.). Governing. Essays in Honour of Donald J. Savoie. London: Mc. Gill - Queen's University Press.

Pindado Sánchez, F. (2015). "El pilar jurídico y conceptual de las políticas locales de transparencia y participación”, en Guía de instrumentos y herramientas para las politicas locales de transparencia y participación ciudadana. FEMP. 
Przeworski, A. (1995). Democracia y Mercado. Cambridge University Press.

Putnam, R. (1976). El estudio comparativo de las élites politicas. Englewood Cliffs: Prentice-Hall.

Ramió, C. y Salvador, M. (2005). Instituciones y Nueva Gestión Pública en América Latina. Barcelona: Fundació CIDOB.

Revue Internationale des Sciences Administratives (2004). "Le partenariat publicprivé: implication por une gouvernance future: l'administration publique entre globalisation et décentralisátion”, Vol. 70, Núm. 2.

Rodríguez Álvarez, J. M. (traducción), Canales Aliende, J. M. (revisión) (1997). La transformación de la gestión pública. Las reformas en los países de la OCDE. Madrid: MAP-BOE.

Sáinz Moreno, F. y Martínez Herrán, G. (2003). "Formación y reforma administrativa: el papel de los institutos de formación en la reforma administrativa". VII Congreso Internacional del CLAD sobre la Reforma del Estado y de la Administración Pública. Panamá, 28-31 Octubre 2003.

Sánchez Morón, M. (2009). "Los directivos públicos: análisis comparado", Cuadernos de Derecho Local, no 19.

Scott, A. (1998). Regions on the World Economy. Oxford: Oxford University Press.

Tourine, A. (1993). Crítica a la modernidad. Madrid: Temas de Hoy.

Tourine, A. (1993). Crítica a la modernidad. Madrid: Temas de Hoy.

TUE (1992). Tratado de la Unión Europea (TUE). Diario Oficial de la Unión Europea (DOUE), C83/13.

Vaquer, J. (2012). "Después de la tecnocracia”, El País, 10 de Diciembre de 2012.

Villoria, M. (2007). "Ética postconvencional e instituciones en el servicio público”, REIS, 117, PP. 109-140. 


\section{Notas}

${ }^{1}$ Ver también Martín-Castilla (2004): "La dimensión ética del directivo público y político, resulta aún más fundamental, si cabe, que en el ámbito privado, ya que la concepción democrática de la Administración por y para servir a la sociedad implica una serie de exigencias tanto desde la sociedad como desde el ámbito individual (obligaciones y requisitos) hacia las personas que encarnan los puestos directivos dentro de la Administración y la política" (Martín-Castilla, 2004). En este sentido Villoria (2007) sostiene que:“(...) es preciso comprender las dinámicas institucionales y modificar el papel del empleado público cognitiva, normativa y regulativamente. Es necesario replantearse qué se espera del empleado público, de dónde le viene su legitimidad, por qué y para qué tiene poder, en quién hay que fijarse isomórficamente y por qué, etc." (Villoria, 2007).

2 “En los años noventa, por referirnos a los procesos más recientes de modernización, se puso en marcha un proceso de reforma administrativa con el Plan de modernización de la Administración General del Estado, que recogió la cultura de la nueva gestión pública, basada en la búsqueda de la calidad, la eficacia y la eficiencia en la prestación de los servicios públicos y que atribuyó al INAP, a través del estudio delphi sobre competencias del directivo público un papel relevante en el proceso de reforma administrativa" (...). La potenciación de las habilidades gerenciales de los directivos públicos se haría mediante el diseño de programas específicos de actualización de conocimientos que incluyeran las mejores prácticas de los sectores público y privado (...)" (Sáinz Moreno y Martínez Herrán, 2003).

3 Rodríguez Álvarez, José Manuel (Traducción); Canales Aliende, José Manuel (revisión) (1997): La transformación de la gestión pública. Las reformas en los países de la OCDE. Madrid, MAP, BOE. 


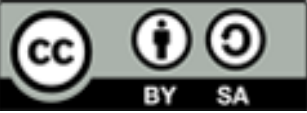

Licencia Creative Commons

Miguel Hernández Communication Journal

mhjournal.org

\section{Cómo citar este texto:}

Bernabé Aldeguer Cerdá (2017): "Los lobbies y la Tecnocracia en la Gestión Pública”, en Miguel Hernández Communication Journal, n8, pp. 465 a 485. Universidad Miguel Hernández, UMH (Elche-Alicante). Recuperado el__ de ___ de 20_ de: @ink del artículo en mhjournal.org] 
